\title{
OPTIMIZATION OF THE SINTERING PARAMETERS FOR MATERIALS MANUFACTURED BY POWDER INJECTION MOLDING
}

\author{
S.V. Zavadiuk, ${ }^{1}$ P.I. Loboda, ${ }^{2}$ T.O. Soloviova, ${ }^{2,4}$ \\ I.Iu. Trosnikova, ${ }^{2}$ and O.P. Karasevska ${ }^{2,3}$
}

UDC 621.762 .5

\begin{abstract}
The properties of sintered and heat-treated steels produced from the Catamold 8740 material by powder injection molding were examined. Parts made of the Catamold 8740 low-alloy mild carbon steel are used in the military, automotive, and other industries where high reliability and resistance to dynamic loads are required. The Catamold 8740 chemical homogeneity was studied as a function of powder injection molding parameters: heating rate, sintering temperature, holding time, and subsequent heat treatment. Microscopic analysis showed that Catamold 8740 was a mechanical mixture of powders in various sizes (carbonyl iron, nickel, $\mathrm{Fe}-\mathrm{Mo}, \mathrm{Fe}-\mathrm{Cr}, \mathrm{Fe}-\mathrm{Si}-\mathrm{Mo}, \mathrm{Fe}-\mathrm{Si}$ ). When the heating rate of the Catamold 8740 powder mixture increased from 2 to $5{ }^{\circ} \mathrm{C} / \mathrm{min}$, the microstructural heterogeneity caused by uneven compaction decreased and the alloy formation process activated at $900-1340^{\circ} \mathrm{C}$. The impact strength of Charpy $V$-notch test samples changed from 10.39 to $11.52 \mathrm{~J} / \mathrm{cm}^{2}$ with higher sintering temperature and heating rate increasing from $2{ }^{\circ} \mathrm{C} / \mathrm{min}$ $\left(1270^{\circ} \mathrm{C}\right)$ to $5{ }^{\circ} \mathrm{C} / \mathrm{min}\left(1340^{\circ} \mathrm{C}\right)$. When holding time increased from 30 to $90 \mathrm{~min}$ at a sintering temperature of $1340^{\circ} \mathrm{C}$, the material became denser, the pores rounded, and the ferrite matrix homogeneous. However, the impact strength decreased by a factor of 1.4 because of coarser grain sizes and brittle fracture. Heat treatment processes reduced the impact strength after sintering. The results obtained were used to optimize the powder injection molding parameters. The influence of chemical and dimensional inhomogeneity of the starting Catamold 8740 powders and sintering kinetics on the structure and mechanical properties of parts operating under impact loads was established.
\end{abstract}

Keywords: powder injection molding, alloy formation process, microstructural heterogeneity, sintering, locally nonuniform sintering.

\section{INTRODUCTION}

In recent years, the powder injection molding (PIM) process has found wider application in powder metallurgy practices. It is also called metal injection molding. This process includes four major stages: preparation of a powder-polymer mixture, injection molding of parts, removal of the binder(debinding), and sintering [1].

${ }^{1}$ Science Industrial Association Fort, Ministry of Internal Affairs of Ukraine, Vinnitsa, Ukraine. ${ }^{2}$ National Technical University of Ukraine 'Igor Sikorsky Kyiv Polytechnic institute', Kyiv, Ukraine. ${ }^{3}$ Kurdyumov Institute for Metal Physics, National Academy of Sciences of Ukraine, Kyiv, Ukraine.

${ }^{4}$ To whom correspondence should be addressed; e-mail: tsolov@iff.kpi.ua.

Translated from Poroshkova Metallurgiya, Vol. 59, Nos. 1-2 (531), pp. 32-41, 2020. Original article submitted September 13, 2019. 
The use of powders with fine particles (from 1 to $20 \mu \mathrm{m}$ ) in the PIM process imparts higher density to the sintered material. This in turn greatly improves the mechanical properties of resultant parts as compared to those produced conventionally. Powder injection molding is advantageous over die compaction in highly homogeneous density throughout the compact.

The starting PIM materials are elemental, prealloy, and master alloy powder mixtures. The choice of powders for the PIM process is closely associated with doping methods. The powder may be of precise chemical composition or be a mixture of different chemical elements and alloys. In the latter case, powders of doping elements are mixed with the base component (for example, carbonyl iron) for the material to acquire desired stoichiometric composition [2, 3]. In a powder mixture, sintering is activated through chemical reaction between the components.

Since PIM is a relatively recent technique, there have not been many studies to ascertain how sintering conditions influence the microstructure of low-alloyed PIM steels. The paper [4] examined the effect of sintering parameters (temperature and holding time) on the mechanical properties of $316 \mathrm{~L}$ corrosion-resistant austenitic steel. The samples were sintered in a hydrogen atmosphere at temperatures from 1320 to $1350^{\circ} \mathrm{C}$ with different holding times (1-4 h). Higher sintering temperatures and holding times decreased the porosity of parts but increased their grain size. The tensile strength and elongation depend on residual porosity, while the elastic limit does not change.

The paper [5] optimized the main sintering parameters: atmosphere, temperature, heating and cooling rates, and holding time. The parameters were optimized with the experimental design matrix applying the Taguchi orthogonal arrays to impart the maximum impact strength to the test samples. The test material was SS316L corrosion-resistant steel powder mixed with a binder (polyethylene glycol, polymethyl methacrylate, paraffin wax, and stearic acid). The results indicate that the greatest effect on the impact strength is exerted by holding time (61.5\%, with $99 \%$ probability) and lower effects by sintering temperature (23.64\%), sintering rate $(9.76 \%)$, and cooling rate $(3.28 \%)$. The paper [5] established that the SS316L material sintered at $1380^{\circ} \mathrm{C}$ for $100 \mathrm{~min}$, the heating rate being $8{ }^{\circ} \mathrm{C} / \mathrm{min}$ and cooling rate $5{ }^{\circ} \mathrm{C} / \mathrm{min}$, acquired the greatest impact strength.

Impact strength is one of the most important mechanical properties of powder steels operating under dynamic loads. Residual porosity (1-2\%) substantially reduces impact resistance. Unfortunately, there is no sufficient information on porousless items with high impact strength produced from powder steels by injection molding.

The objective of this effort is to determine how sintering parameters influence the microstructure, phase composition, and impact strength of the PIM material and optimize sintering parameters to impact high mechanical properties to the parts.

\section{Experimental Procedure}

To make test samples with the PIM process, the Catamold 8740 material produced by BASF Company (Germany) was used. The material has the following chemical composition, \%: $0.45-0.55 \mathrm{C}, 0.4-0.6 \mathrm{Cr}, 0.25-$ $0.4 \mathrm{Mo}, 0.5-0.8 \mathrm{Ni}, 0.3-0.55 \mathrm{Si}$, and $\mathrm{Fe}$ as the base element.

The doping mixture has the following composition, \%: $52 \mathrm{Fe}-48 \mathrm{Cr}, 90 \mathrm{Fe}-10 \mathrm{Mo}$, and $89 \mathrm{Fe}-11 \mathrm{Si}$. To determine the sizes of starting powder particles, Catamold 8740 granules were heated at $600^{\circ} \mathrm{C}$ in a hydrogen atmosphere to remove the polymer binder. According to electron microscopy, the carbonyl iron particles range from 1 to $5 \mu \mathrm{m}$ and the master alloy particles from 6 to $30 \mu \mathrm{m}$.

The master alloy powders were gas-atomized to make their particles spherical. The carbonyl iron powder produced by thermal decomposition has much smaller particles than those of the doping powders.

The samples were fabricated employing a Power 250/50 injection molding machine (Engel, Austria) with a modified injection cylinder. The binder was catalytically removed in a CD3045 furnace (ELNIK, USA). The secondary binder component (polyethylene) was removed by thermal annealing in a nitrogen atmosphere (99.994\%, $40^{\circ} \mathrm{C}$ dew point). The test samples were sintered using a MIM3045 horizontal vacuum furnace (ELNIK, USA). The sintered samples (Table 1) were $55 \mathrm{~mm} \times 10 \mathrm{~mm} \times 5 \mathrm{~mm}$ rectangles. 
TABLE 1. Properties of the Catamold 8740 Material Depending on Sintering Conditions

\begin{tabular}{|r|c|c|c|c|}
\hline \multicolumn{3}{|c|}{ Sintering conditions } & \multirow{2}{*}{ Shrinkage, $\%$} & \multirow{2}{*}{ Density, $\mathrm{g} / \mathrm{cm}^{3}$} \\
\cline { 1 - 2 }$T,{ }^{\circ} \mathrm{C}$ & Heating rate, ${ }^{\circ} \mathrm{C} / \mathrm{min}$ & Holding time, min & & \\
\hline \multirow{2}{*}{900} & 5 & 60 & - & - \\
1270 & 2 & 30 & 20.81 & 7.45 \\
1270 & 5 & 30 & 18.72 & 7.03 \\
1270 & 5 & 120 & 19.98 & 7.30 \\
1340 & 5 & 30 & 20.429 & - \\
1340 & 5 & 90 & 21.18 & \\
\hline
\end{tabular}

The length of the test samples was measured after sintering to determine shrinkage $\gamma$ as follows:

$$
\gamma=\left(\left(L_{\mathrm{s}} / L_{\mathrm{m}}\right)-1\right) \cdot 100 \%,
$$

where $L_{\mathrm{s}}$ is the length of the sintered sample, $\mathrm{mm} ; L_{\mathrm{m}}$ is the length of the molded sample, $\mathrm{mm}$. Data on the shrinkage and density (determined by hydrostatic weighing in accordance with standard procedure) of the material at different sintering parameters are provided in Table 1.

The sintered samples were subjected to heat treatment. The heat treatment included quenching in nitrate at $280^{\circ} \mathrm{C}$. The samples were tempered in a batch furnace at $550^{\circ} \mathrm{C}$ with a holding time of $60 \mathrm{~min}$. The tempered samples acquired a sorbite structure with 30-35 HRC hardness.

The microstructure was examined with a REM-106I scanning electron microscope (Selmi, Ukraine). The chemical composition was determined by X-ray fluorescence with an Expert 3L analyzer (Ukraine).

The samples were subjected to X-ray diffraction employing an Ultima IV diffractometer (Rigaku, Japan) in $\mathrm{Cu}-K_{\alpha}$ radiation $\left(\lambda_{\mathrm{Cu}-K_{\alpha 1}}=0.154187 \mathrm{~nm}\right)$ with step angle $2 \theta=0.04^{\circ}$, exposure time of $2 \mathrm{sec}$, and rotation. X-ray diffraction patterns were processed with the RIR software package.

The impact strength was determined on Charpy V-notch samples (as per GOST 9454-78).

\section{EXPERIMENTAL RESULTS AND DISCUSSION}

The Catamold 8740 material is a mixture of carbonyl iron and master alloys (Fig. 1). Fine iron particles have greater total surface energy and thus activate the surface diffusion at early sintering stages. The iron powders thus sinter at lower temperatures than the master alloy powders do and the main sintering problem is to promote homogeneous microstructure.

The thin oxide film on powder particles in the $\mathrm{Fe}-\mathrm{C}$ system reduces at about $700-800^{\circ} \mathrm{C}$ in an inert environment. When iron combines with doping elements that have a similar tendency to oxidation (Ni, Mo), the

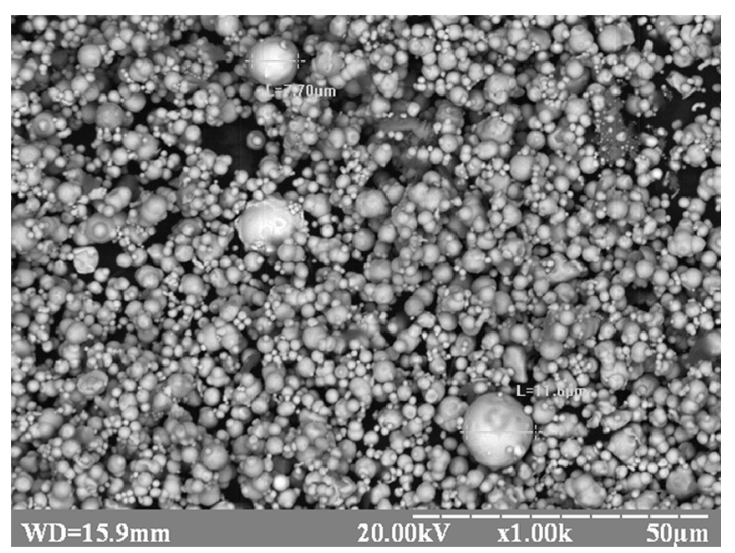

Fig. 1. Microphotograph of the starting Catamold 8740 powder mixture 

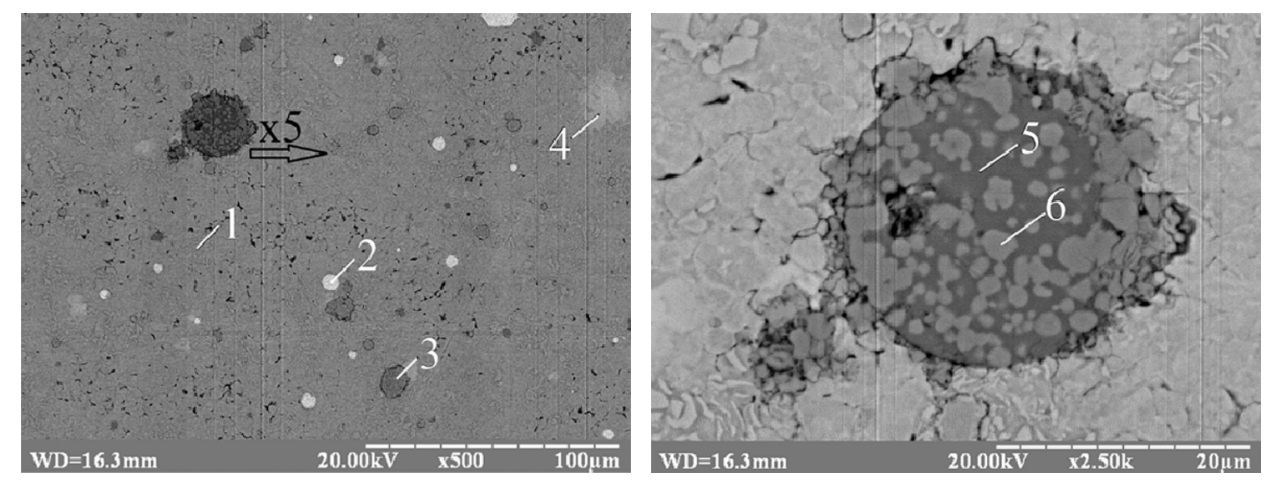

\begin{tabular}{|c|r|r|r|r|r|r|}
\hline \multirow{2}{*}{$\begin{array}{c}\text { Chemical } \\
\text { element }\end{array}$} & \multicolumn{7}{|c|}{ Sample No. } \\
\cline { 2 - 7 } & 1 & 2 & 3 & \multicolumn{1}{|c|}{4} & 5 & 6 \\
\hline $\mathrm{Si}$ & 0.08 & 0.39 & 0.18 & 0.05 & 24.32 & 12.61 \\
$\mathrm{Mn}$ & 0.40 & & 1.00 & 0.04 & 0.22 & 0.31 \\
$\mathrm{Fe}$ & 99.49 & 77.32 & 64.68 & 42.79 & 75.16 & 86.8 \\
$\mathrm{Cr}$ & 0.02 & 0.57 & 33.99 & 0.10 & 0.19 & 0.20 \\
$\mathrm{Ni}$ & & 0.56 & & 56.37 & & \\
$\mathrm{Mo}$ & & 21.16 & & 0.43 & & 0.04 \\
$\mathrm{Ca}$ & & & 0.15 & 0.21 & 0.10 & \\
$\mathrm{~S}$ & 0.01 & & & & & \\
\hline
\end{tabular}

Fig. 2. Microstructure of the Catamold 8740 material sintered at $900^{\circ} \mathrm{C}$ with a holding time of 60 min and its local chemical composition in samples 1-6

oxide films do not change their oxidation behavior. However, difficulties arise when they are doped with elements such as $\mathrm{Cr}$ and $\mathrm{Si}$. They are more capable of forming strong oxide films than iron is, especially when heated to the sintering temperature $\left(400-1200^{\circ} \mathrm{C}\right)$. In early sintering, the material is a porous metallic matrix with doping inclusions. The chemical inhomogeneity of the material sintered at $900^{\circ} \mathrm{C}$ with a holding time of $60 \mathrm{~min}$ is shown in Fig. 2.

The microstructure of the material at higher heating rates is shown in Fig. 3. Higher heating rates promote more homogeneous microstructure with pores being uniformly distributed over the cross-section. This is attributed to the fact that high heating rates inhibit surface diffusion in the early sintering stage and, as a result, encourage greater volume diffusion of doping atoms at elevated temperatures.

Figure 4 demonstrates how holding time influences the Catamold 8740 microstructure. Greater holding times favorably influence the material's structural homogeneity because of longer diffusion of doping elements into the iron matrix.
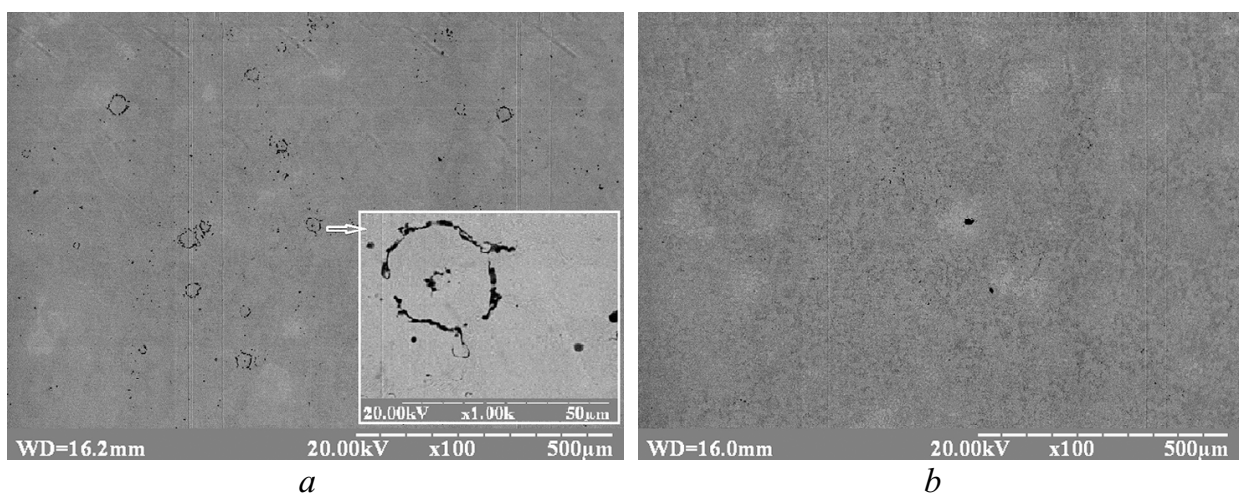

Fig. 3. Microstructure of the Catamold 8740 material sintered at $1270^{\circ} \mathrm{C}$ with a holding time of $30 \mathrm{~min}$ and a heating rate of $2(a)$ and $5^{\circ} \mathrm{C} / \mathrm{min}(b)$ 


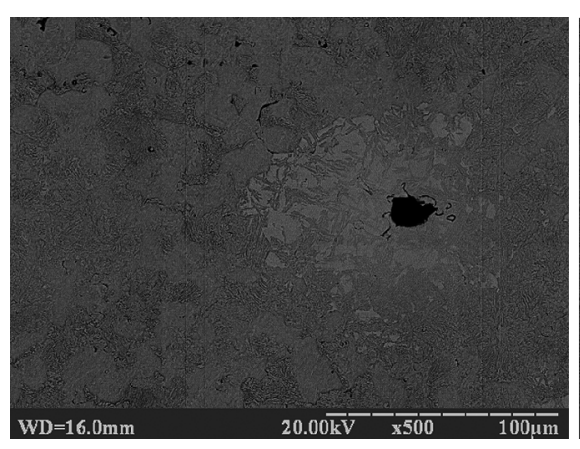

$a$

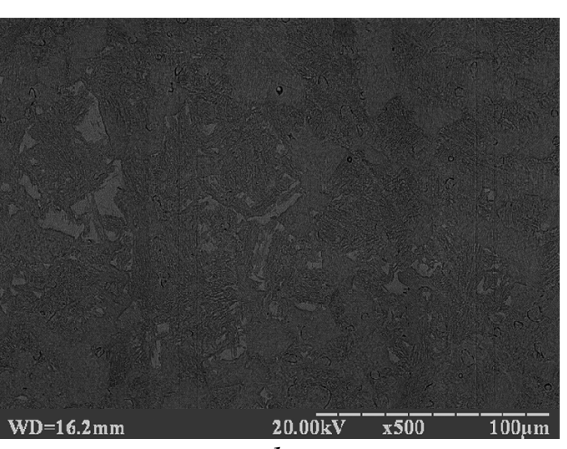

$b$

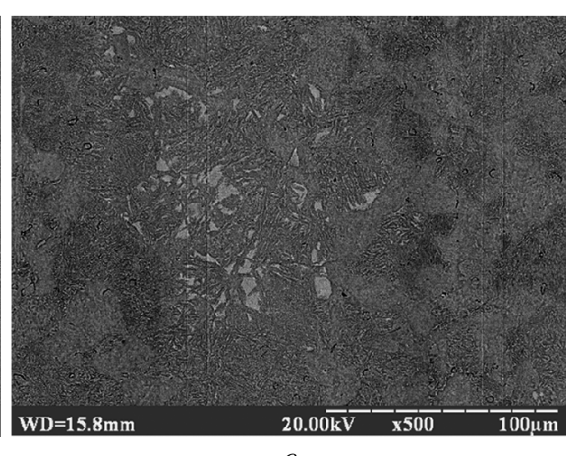

c

Fig. 4. Microstructure of the Catamold 8740 material sintered at $1270(a, b)$ and $1340^{\circ} \mathrm{C}(c)$ at a heating rate of $5^{\circ} \mathrm{C} / \mathrm{min}$ and a holding time of $30(a, c)$ and $120(b) \mathrm{min}$

The sintered samples were subjected to heat treatment. The heat treatment resulted in tempered sorbite, which is a eutectoid mixture of cementite and ferrite (Fig. 5). The X-ray diffraction patterns have very small fine reflections being indicative of additional phases. When sintering temperature increases and heat treatment is applied, the additional phases become more evident; their reflections in the X-ray diffraction pattern match reflections of carbides and perhaps oxides of $\mathrm{Mo}, \mathrm{Cr}$, and other elements (according to the RIR software).

Comparison of the iron line width at large angles on the surface and at the cross-section indicates that there are microstresses and the size of coherent scattering domains (CSDs) changes at the cross-section. Microstresses

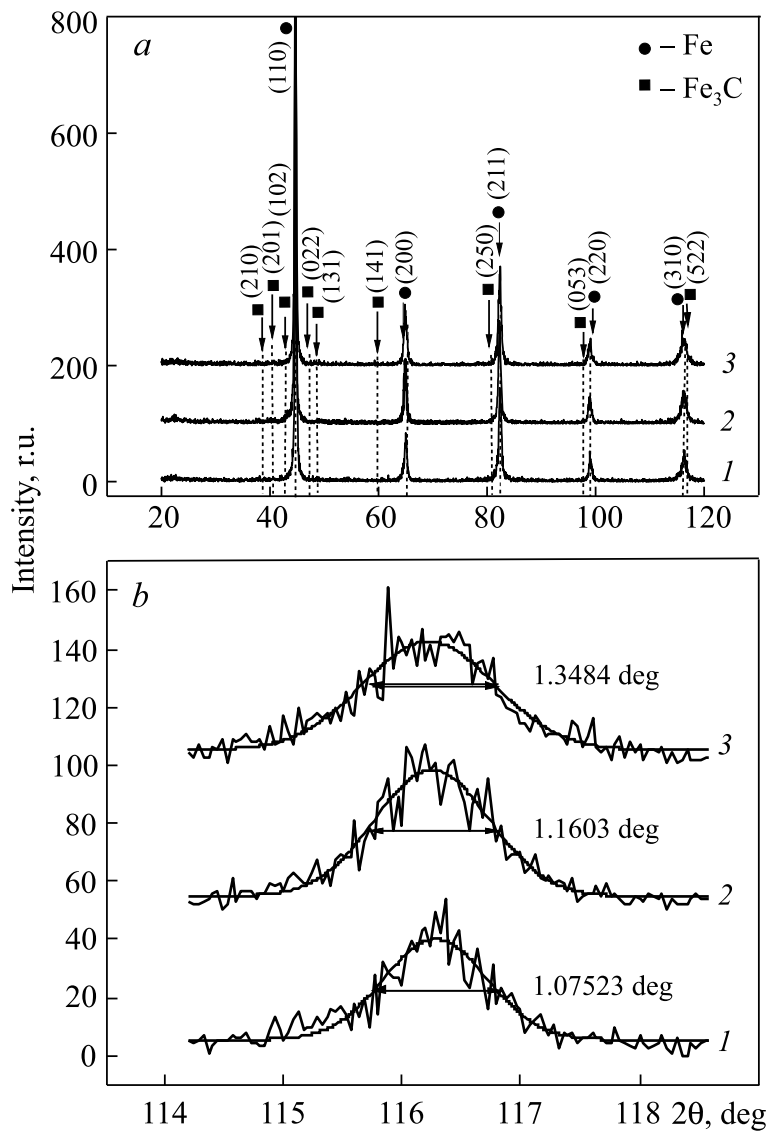

Fig. 5. X-ray diffraction patterns $(a)$ and intensity of the $\{310\}$ Fe line intensity $(b)$ for the Catamold 8740 material produced in different sintering conditions $(1,2)$ and subsequent heat treatment $(3)$ : 1) $\left.1270^{\circ} \mathrm{C}, 2{ }^{\circ} \mathrm{C} / \mathrm{min}, 30 \mathrm{~min} ; 2,3\right) 1340^{\circ} \mathrm{C}, 5^{\circ} \mathrm{C} / \mathrm{min}, 30 \mathrm{~min}$ 


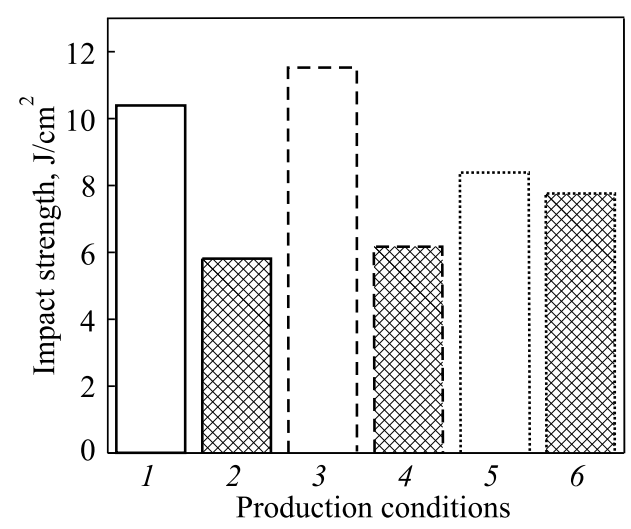

Fig. 6. Impact strength of the Catamold 8740 material after sintering $(1,3,5)$ and subsequent heat treatment $(2,4,6)$ in different conditions: 1,2$\left.) 1270^{\circ} \mathrm{C}, 2{ }^{\circ} \mathrm{C} / \mathrm{min}, 30 \mathrm{~min} ; 3,4\right) 1340^{\circ} \mathrm{C}, 5^{\circ} \mathrm{C} / \mathrm{min}$, $30 \mathrm{~min} ; 5$, 6) $1340^{\circ} \mathrm{C}, 5^{\circ} \mathrm{C} / \mathrm{min}, 90 \mathrm{~min}$

were calculated with X-ray diffraction data. As turned out, they are 1.2 times higher after heat treatment than after sintering, which can influence the mechanical properties.

To determine the optimum sintering conditions for the Catamold 8740 material, we measured its impact strength. The experimental results are provided in Fig. 6. The highest impact strength is shown by the samples sintered at $1340^{\circ} \mathrm{C}$ at a heating rate of $5^{\circ} \mathrm{C} / \mathrm{min}$ and a holding time of $30 \mathrm{~min}$. The impact strength decreases when holding time increases to $90 \mathrm{~min}$. The grains commonly coarsen in long-term sintering. However, the grain size decreases after heat treatment and is the same (size number 12 as per DSTU ISO 643:2009) for all samples. The sintering temperature influences other characteristics as well. Table 1 indicates that density and shrinkage increase with sintering temperature, thus improving the mechanical properties. The noticeable increase in the impact strength of the samples sintered at $1340^{\circ} \mathrm{C}$ at a heating rate of $5{ }^{\circ} \mathrm{C} / \mathrm{min}$ and a holding time of $30 \mathrm{~min}$ and subjected to subsequent heat treatment compared to other samples is associated with simultaneous improvement of the chemical homogeneity and density.

Figure 7 shows fracture patterns for the sintered samples. The fracture surface is viscous, with fine pits and a small number of brittle nanocrystalline fracture facets. With grain refinement, the impact strength increases; this is associated with greater absorption of impact energy in the fine-grained structure.

The fracture surface (Fig. 7) of the samples sintered at a heating rate of $2{ }^{\circ} \mathrm{C} / \mathrm{min}$ has local heterogeneities that are weakly bonded to the main matrix, as we can also see on section images (Fig. 3). This in turn can significantly reduce the mechanical properties. No local heterogeneities were found on the fracture surface when the test samples were sintered at a heating rate of $5^{\circ} \mathrm{C} / \mathrm{min}$. Figure $7 a$ illustrates a round pore resulting from incomplete
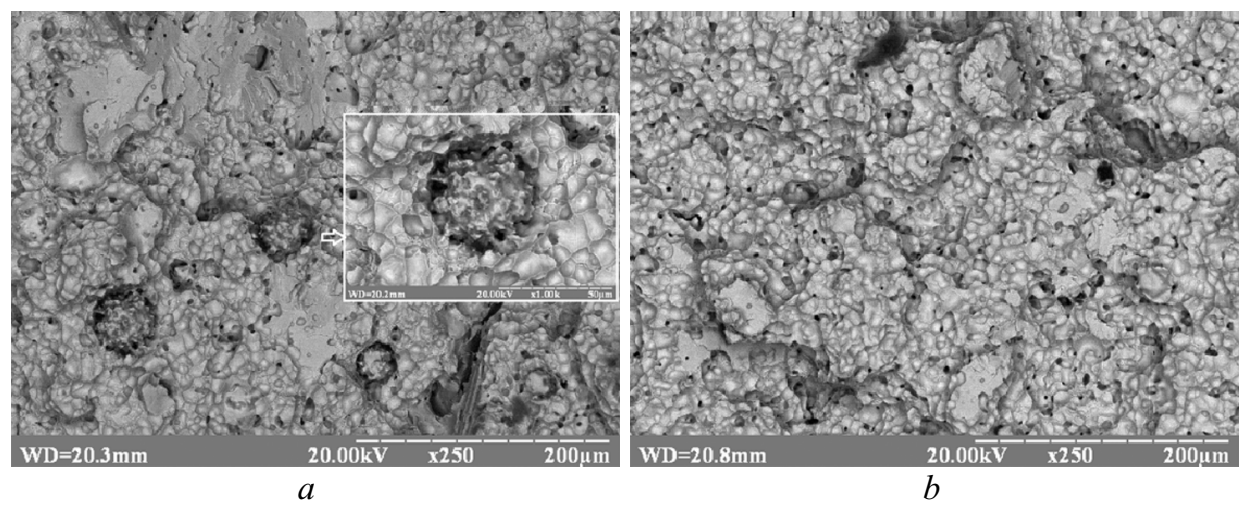

Fig. 7. Fracture surface after measuring the impact strength of the Catamold 8740 material produced at different sintering parameters: a) $1270^{\circ} \mathrm{C}, 2^{\circ} \mathrm{C} / \mathrm{min}, 30 \mathrm{~min}$; b) $1340^{\circ} \mathrm{C}, 5^{\circ} \mathrm{C} / \mathrm{min}, 30 \mathrm{~min}$ 
diffusion of doping elements into the iron matrix. This structural heterogeneity may be caused by the presence of FeSi master alloy in the starting state, whose silicon content exceeds $13 \mathrm{wt} . \%$. According to the Fe-Si phase diagram, silicon $(\geq 13 \%)$ interacts with iron to form a liquid phase below the sintering temperature to intensify shrinkage in local areas with increased silicon content. Therefore, the material sinters to reach $100 \%$ density at the center of the round pore and separates from the main iron matrix. Such heterogeneities are difficult to reveal since the material shows high density and shrinkage factor (Table 1) when the samples are measured hydrostatically. However, the material inside a round pore (Fig. 7a) is not bonded to the main material and bears no mechanical load.

In general, silicon is widely used in metallurgy. It is introduced in small amounts to molten steels as a deoxidizer. In amounts above $0.6 \%$, silicon is considered a doping element. Silicon-doped steels have high elastic and yield limits and high oxidation resistance. In addition, when powder steels are produced from a mixture of master alloys, silicon interacts with oxide films on powder particles to improve the diffusion of elements. Nevertheless, this paper indicates that incorrect choice of the sintering parameters at an unbalanced content of doping elements in the master alloys and the formation of agglomerates can lead to local heterogeneity in the material and thus decrease the mechanical properties of sintered parts.

\section{CONCLUSIONS}

The microstructure of the Catamold 8740 material becomes more homogeneous and the alloy formation process more complete when the heating rate increases from 900 to $1340^{\circ} \mathrm{C}$. The microstructural chemical homogeneity of sintered samples improves with the heating rate increasing from 2 to $5{ }^{\circ} \mathrm{C} / \mathrm{min}$ because the shrinkage of compacts slows down at low temperatures, promoting a greater number of contacts between the particles and accelerating the formation of alloys at higher sintering temperatures $\left(1340^{\circ} \mathrm{C}\right)$.

According to tests of the sintered V-notch samples, the impact strength of the Catamold 8740 material increases by $33 \%$ when their microstructure becomes more homogeneous.

\section{REFERENCES}

1. D.F. Heaney, Handbook of Metal Injection Molding, Wood Head Publishing (2012), p. 612.

2. $\quad$ R.M. German, Injection Molding of Metals and Ceramics, Metal Powder Industry Federation (1997), pp. 125.

3. R.M. German, Sintering: from Empirical Observations to Scientific Principles, Butterworth-Heinemann (2014), p. 544.

4. Tae Shik Yoon, You Hwan Lee, and Sang Ho Ahn, "Effect of sintering conditions on the mechanical properties of metal injection molded 316L stainless steel," J. Iron Steel Inst. Jpn. Int., 43, No. 1, 119-126 (2003).

5. Pachauri Praveen and Hamiuddin Mohammed, "Effect of sintering process parameters in metal injection molding process on impact toughness of sintered parts," Int. J. Adv. Mater. Metall. Eng., 2, No. 1, 23-33 (2016).

6. T. Barriere, B. Liu, and J.C. Gelin, "Determination of the optimal parameters in the metal injection molding from experiments and numerical modeling," J. Mater. Process. Technol., 636-644 (2003).

7. D.F. Heaney, P. Zauner, C. Binet, K. Cowan, and J. Piemme, "Variability of powder characteristics and their effect on dimensional variability of powder injection molded components," Powder Metall., 47, No. 2, $145-150$ (2004).

8. Standard 59, Method for Determination of Charpy Impact Energy of Unnotched Metal Injection Molded Test Specimens, Metal Powder Industries Federation, New Jersey, USA (2019), p. 2.

9. GOST 9454-78, Metals. Method of Impact Bending Testing at Low, Room, and High Temperatures [in Russian], Izdatelstwo Standartov, Moscow (1979), p. 13. 